\title{
THE GENETICS OF ADDICTIONS: UNCOVERING THE GENES
}

\section{David Goldman, Gabor Oroszi and Francesca Ducci}

Abstract | The addictions are common chronic psychiatric diseases that today are prevented and treated using relatively untargeted and only partially effective methods. The addictions are moderately to highly heritable, which is paradoxical because these disorders require use; a choice that is itself modulated by both genes and environment. The addictions are interrelated and related to other psychiatric diseases by common neurobiological pathways, including those that modulate reward, behavioural control and the anxiety or stress response. Our future understanding of addictions will be enhanced by the identification of genes that have a role in altered substance-specific vulnerabilities such as variation in drug metabolism or drug receptors and a role in shared vulnerabilities such as variation in reward or stress resiliency.

AFFECTIVE DISTURBANCE An abnormal or inappropriate emotion or mood.

POINT PREVALENCE The proportion of individuals who have a phenotype at a specified point in time or within a defined timeframe (for example, 1 year).

DISABILITY ADJUSTED LIFE YEAR

The years of life that are lost due to premature mortality or disability.

PSYCHOPATHOLOGY A psychiatric disease, or the manifestation of a psychiatric disease.

Laboratory of Neurogenetics, National Institute on Alcohol Abuse and Alcoholism, Rockville, Maryland 20852, USA. Correspondence to D.G. e-mail: dgneuro@box-d.nih.gov doi:10.1038/nrg1635
Addictions are psychiatric disorders that are associated with maladaptive and destructive behaviours, and that have in common the persistent, compulsive and uncontrolled use of a drug or an activity. Addictive agents induce adaptive changes in brain function; these changes are the bases for tolerance and for the establishment of craving, withdrawal and aFFECTIVE Disturbance, which persist long after consumption ceases ${ }^{1}$. This self-maintaining and progressive neurobiology of addictions makes them chronic and relapsing disorders.

The addictions are a worldwide public-health crisis, and exert corrosive effects at family and societal levels, leading even to the narco-political and narco-economic domination of countries and regions. The World Health Organization (WHO) estimated that there are 2 billion alcohol users, 1.3 billion tobacco users, and 185 million users of illicit drugs (see the WHO reports in the Online links box). In 2001, these three categories together contributed to $12.4 \%$ of deaths worldwide (see the WHO reports in the Online links box). According to the National Epidemiologic Survey on Alcohol and Related Conditions (NESARC) ${ }^{2}$, the one-year POINT PREVALENCE of DSM-IV (the fourth edition of the Diagnostic and Statistical Manual of Mental Disorders issued by the American Psychiatric Association) substance-use disorders (excluding nicotine) is $9.35 \%$ in the United States, representing 19.4 million adults (BOX 1). As well as causing 590,000 deaths per year in the United States, addictive drugs also cause injury or illness to almost 40 million individuals ${ }^{3}$. On a population basis, alcoholism alone subtracts an average of 4.2 Disability adjusted life Years (DALYs) per person, tobacco subtracts 4.1 DALYs and illicit drugs subtract 0.8 DALYs. For comparison, AIDS subtracts 6.0 DALYs and type 1 diabetes subtracts 0.1 DALYs ${ }^{4}$. The addiction disease burden is unequally distributed across countries; drugs have a higher impact in the United States and Europe than in developing countries where life expectancies are shorter (see the WHO reports in the Online links box).

Environmental and genetic factors contribute to individual differences in vulnerability to initiating use of addictive agents and in vulnerability to the shift from use to addiction. Cross-sectional studies on large twin samples also indicate that a mixture of environmental and genetic influences are shared between diseases ${ }^{5}$ and provide a link between the normal range of behavioural variation and PsYchopathologY $Y^{6,7}$. However, because addictions are in theory entirely preventable by law or individual choice, it has been argued that addictions are a low priority for genomic research ${ }^{4}$. Substance use shapes patterns of abuse and dependence, and conversely, addictive drugs are largely consumed by 
POLYGENICITY

A model of genetic determinism in which many alleles function in combination to produce a phenotype.

\section{HETEROGENEITY}

A model of genetic determinism in which different alleles lead to the same phenotype in different allele can suffice to produce the

HERITABILITY

An estimate of the genetic component of liability, which ranges from zero to one.

ADDICTION LIABILITY The relative potential of an agent to lead to addiction.

\section{ABUSE}

Substance abuse is a disease that is operationally defined using objective criteria such as those issued by the American Psychatric Association and the World Health Organization. individuals, but an individual phenotype.

addicted individuals ${ }^{8}$. Addictive substances are widely used worldwide 9 (FIG. 1). However, voluntary or enforced choice has met with partial success. Restrictions generally reduce addictions but are variably applied. Furthermore, the addictions encompass non-substance related behaviours that are widespread and that might access the same neurobiological pathways that modulate reward ${ }^{10}$, impulsive and compulsive behaviour, and mood. These diverse behaviours, including binge eating, compulsive gambling and playing video games, resemble the substance addictions in their clinical course and harmful effect. Therefore, the public-health impact of gene discovery for the addictions is potentially very large, as Merikangas and Risch ${ }^{4}$ noted. The origins of addiction vulnerability are complex and wide-ranging; the underlying genetic factors need to be identified to solve the puzzle of what causes these pervasive and relatively intractable disorders. Fortunately, the establishment of widely accepted definitions has created a unifying framework for research and for the clinical treatment of disorders that frequently share neurobiological and clinical course ${ }^{11}$ (BOXES 1,2).

In this review, we describe our current understanding of addictions. We begin by comparing their mode of inheritance and then discuss the nature of inherited factors, including the genetic risk factors that are shared across diseases versus disease-specific factors, and evidence for POLYGENICITY and HETEROGENEITY. We describe the progress that has been made in gene mapping, including recent work that has used intermediate phenotypes as predictors of vulnerability, and studies of candidate addiction-predisposing genes in animal

\section{Box 1 | Definition and classification of addictions}

Clinical addictions are generally diagnosed using the Diagnostic and Statistical Manual of Mental Disorders (DSM) issued by the American Psychiatric Association (APA), or using the International Classification of Disease (ICD) of the World Health Organization (WHO). These manuals are also used in research. The most recent versions of both systems (DSM-IV and ICD-10) recognize two categories: ABUSE (DSM-IV) or harmful use (ICD-10) and dependence. DSM-IV definitions of abuse and dependence are shown in BOX 2. Diagnoses can be made with high reliability; $\kappa$-values (a widely used coefficient of reliability that ranges from -1.0 to +1.0 ) are more than 0.70 for both DSM-IV and ICD-10 current alcohol dependence diagnoses ${ }^{11}$. Addiction diagnoses are not aetiologically based, but are descriptive and syndromic, based on clusters of symptoms and clinical course ${ }^{104}$. This issue limits their usefulness for research into the causes of addictions and is failing to promote individualized treatment and prevention.

The clinically heterogeneous nature of addictions led to sub-classifications, usually A versus $B^{54,105}$. More complex subdivisions are sometimes made ${ }^{106-109}$ that take into account age, age at onset, gender, psychiatric comorbidity and clinical course $^{105,107}$. For alcoholism, type A (for example, Cloninger type I) comprises approximately two-thirds of alcoholics and is characterized by later onset, slower course and better prognosis. Type B (for example, Cloninger type II) is characterized by stronger familial clustering, antisocial behaviour, earlier onset, rapid course and poorer prognosis. A frequently identified subtype is that of the negative affect or internalizing alcoholic, who is characterized by high levels of anxiety and depression ${ }^{106,107}$. A and B distinctions are largely extendable to other addictions ${ }^{110,111}$. Future versions of the DSM will probably incorporate dimensional indices such as age at onset, years of drug use, frequency and quantity of use. Future categorizations might also handle better the cross-connections between addictions and other psychopathologies.

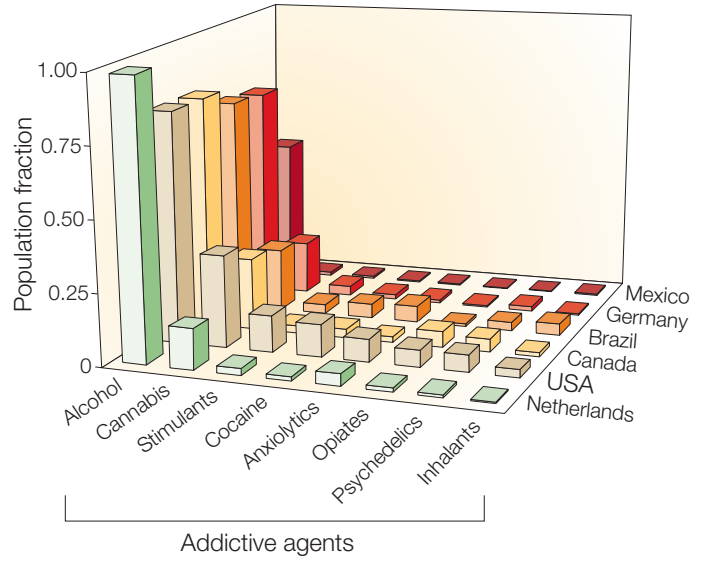

Figure 1 | Lifetime prevalence of substance use in 6 countries. Alcohol use is defined as having consumed 12 or more drinks in at least 1 year. Other drug use is defined as reporting use of the drug more than five times ever. Data are from Vega et al. ${ }^{9}$

models. We conclude by discussing the integration of genotypes into diagnosis; this goal is particularly timely given the enormous public-health impact of addictions and the potential power of precisely and inexpensively defined genotypes associated with these heritable diseases.

\section{Inheritance of addictions}

The inheritance of addictions has been evaluated in many ways, including studies on families and adoptees, but the cornerstone of our knowledge comes from the patterns of correlations in monozygotic (MZ) and dizygotic (DZ) twins.

Addictions are among the most heritable of psychiatric disorders, as shown in studies of large, carefully characterized cohorts of twins (TABLE 1), including epidemiologically ascertained cohorts from Virginia, USA, and Australia. HERITABILITIES range from 0.39 (for hallucinogens) to 0.72 (for cocaine) (FIG. 2a). These moderate to high heritabilities are seemingly paradoxical: addiction depends initially on individual choice to use an addictive agent (so, if a person chooses to use a drug, how can addiction to the drug be heritable?) and wide variations in ADDICTION LIABILITY are observed across time and space. However, heritability studies are generally carried out within populations and age-cohorts that share a substantial likelihood of exposure. Furthermore, it is becoming clear that susceptibility to several complex diseases - coronary artery disease, obesity, cancer and AIDS - is genetically influenced, but also depends profoundly on lifestyle choices. It should also be emphasized that, within populations, exposures are frequently pervasive (for example, exposure to nicotine, alcohol, gambling and caffeine in the United States) and that twin studies therefore cannot expose the full range of genotypes that underlie addiction. In addition, certain individuals are predisposed to initiate use. Heritabilities for initiation and use are generally lower than for dependence, but are still significant ${ }^{12,13}$. Finally, heritabilities should not be overinterpreted as 


\section{Box 2 | Formal criteria for diagnosing substance-use disorders}

Substance-use disorders, including abuse and dependence, are maladaptive patterns of use that lead to clinically significant impairment or distress. According to the definition that is included in the frequently used Diagnostic and Statistical Manual of Mental Disorders (DSM, issued by the American Psychiatric Association), the diagnosis of substance dependence requires at least three of seven criteria and the diagnosis of substance abuse requires one of four criteria. The criteria listed below are those described in the fourth edition of DSM (DSM-IV), published in 1994.

The seven criteria for substance dependence

- The need for markedly increased amounts of the substance to achieve intoxication or desired effect, or diminished effect with continued use of the same amount (tolerance).

- Withdrawal syndrome or use of the substance to relieve or avoid withdrawal symptoms.

- One or more unsuccessful efforts to cut down or control use.

- Use in larger amounts or over a longer period than intended.

- Important social, occupational or recreational activities are given up or reduced because of substance use.

- A large amount of time is spent in activities that are necessary to obtain, to use or to recover from the effects of the substance.

- Continued use despite knowledge of having persistent or recurrent physical or psychological problems that are caused or exacerbated by the substance.

The four criteria for substance abuse

- Recurrent use resulting in a failure to fulfil the main obligations at work, school or home.

- Recurrent use in physically hazardous situations.

- Recurrent substance-related legal problems.

- Continued use despite persistent or recurrent social or interpersonal problems that are caused or exacerbated by the substance.

For both disorders, symptoms must occur within the same 12-month period. The abuse diagnosis is excluded in patients who have ever been dependent.

\section{RESILIENCY}

The ability to withstand mental or physical stress.

OLIGOGENICITY

A model of genetic

determinism in which a few

alleles function in combination

to produce a phenotype.

HAPLOTYPE

A combination of alleles at

different loci on the same

chromosome. absolute levels of genetic influence. Heritabilities are estimates that are based on correlations, and are subject to sampling and methodological errors, so the accuracy of diagnosis or the measurement error places a limit on the strength of correlations. Because the total variance includes measurement error and gene-environment covariance, the role of unshared environmental factors cannot be calculated by subtracting heritable variance in liability from total variance.

Addiction liability and heritability. Drugs differ in their addiction liability. Addictive liability should correlate with heritability of addiction if variation in the neurobiological basis of addiction is what is being inherited. Although addiction liability is difficult to quantify, Goldstein and Kalant ranked relative risks of addiction to different classes of substances ${ }^{14}$. Using those risk rankings as crude indicators, it seems that addiction liability predicts heritability moderately well, as shown in FIG. 2b. Cocaine and opiates, among the most addictive of substances, are among the most heritable. On the other hand, hallucinogens are among the least addictive, and are also the least heritable. These data seem to point towards an inheritance of variation in the core neurobiological basis of addiction, such as the pathways that mediate reward, behavioural control, obsessionality, compulsivity, or stress and anxiety response. If genes that underlie such variation are detected, they might be informative across addiction disorders and for other behavioural differences that are determined by the same neurobiological processes.

Mode of inheritance. The addictions are inherited as common, complex diseases that show no obvious pattern of Mendelian transmission ${ }^{15}$. However, beyond the importance of environmental interactions, the origin of the complexity is poorly understood. It is tempting to imagine that addictions are polygenic, with vulnerability arising from the simultaneous impact of functional variations at several genes. This model of composite, vulnerable neurobiological processes is consistent with the variety of pathways involved, and the numerous genes involved in these pathways, any one of which could have functional genetic variants. Under a polygenic model, the simultaneous inheritance of many genetic variants (shown as a combination of puzzle pieces in FIG. 3a) is necessary for expression of the disease. However, the molecular complexity of the neural systems can also lead to genetic heterogeneity: a single genetic variation determines vulnerability and RESILIENCY, but different variants (FIG. 3a) can suffice for expression of the disease in different individuals and families. Polygenicity and heterogeneity have a different effect on MZ:DZ twin concordance ratios (FIG. 3b). These ratios can thereby provide a test to investigate whether a disease is polygenic. This is because MZ twins share all alleles but DZ twins are unlikely to share a combination of alleles. Certain psychiatric diseases (for example, autism and schizophrenia) have high or moderately high MZ:DZ ratios, indicating they might be polygenic or at least oligogenic. The MZ:DZ twin concordance ratios (FIG. 4) reveal no powerful imprint of polygenicity on the inheritance of most addictions, although modest polygenic effects are sometimes seen. For example, the ratio for cocaine is almost $4: 1$, invoking OLIGOGENICITY or perhaps the effect of a single recessive allele. In most other cases, the MZ:DZ ratios converge to 2:1, which is consistent with alleles of individual effect, and the genetic heterogeneity model. The relative importance of polygenicity versus heterogeneity has implications for the potential diagnostic use of genetic markers and for strategies to identify gene effects. High within-gene heterogeneity (for example, of the breast cancer 1 , early onset (BRCA1) gene in certain cancers) can cause the failure of case-control association analysis using HAPLOTYPEs, because different risk alleles will often reside on different haplotypes. By contrast, individual families and isolated populations could be more useful under a model of high genetic heterogeneity. Under a model of polygenicity and strong epistatic effects, some loci might be undetectable except by two-locus analysis, which should be used with trepidation because of the geometric increase in the number of tests carried out, and the consequent loss of power. 


\begin{tabular}{|c|c|c|c|c|}
\hline $\begin{array}{l}\text { Addictive } \\
\text { agents }\end{array}$ & MZ pairs & DZ pairs & Surveys & References \\
\hline Cannabis & 4,348 & 3,311 & VTR, MTRS, ATR, VETR & $13,128-131$ \\
\hline Sedatives & 2,676 & 2,082 & VTR, MTRS, VETR & $13,128,131$ \\
\hline Stimulants & 1,302 & 910 & VTR, MTRS & $13,128,132$ \\
\hline Cocaine & 1,287 & 919 & VTR, MTRS & $13,128,133$ \\
\hline Hallucinogens & 2,582 & 1,988 & VTR, VETR & 13,131 \\
\hline Opiates & 1,930 & 1,564 & MTRS, VETR & 128,131 \\
\hline Smoking & 5,664 & 4,956 & $\begin{array}{l}\text { VETR, STR, NAS-NRCTR, } \\
\text { VTR }\end{array}$ & $18,134-137$ \\
\hline Alcohol* $^{*}$ & 5,682 & 4,215 & $\begin{array}{l}\text { ATR, VTR, VETR, } \\
\text { NAS-NRCTR }\end{array}$ & $134,138-141$ \\
\hline Caffeine ${ }^{\ddagger}$ & 3,480 & 3,517 & NAS-NRCTR, VTR & $18,142,143$ \\
\hline Gambling & 1,869 & 1,490 & VETR & 144 \\
\hline
\end{tabular}

*Studies measuring the heritability of alcohol dependence were used to compute the mean heritability estimate for alcoholism. The US National Academy of Sciences-National Research Council (NAS-NRC) ${ }^{141}$ study, which measured the heritability of the volume of alcohol consumed, was used only for computing the monozygotic (MZ):dizygotic (DZ) twin ratio. ${ }^{\text {TThe Hettema and }}$ Corey ${ }^{142}$ study was used for caffeine consumption weighted heritability estimates, but not for $M Z: D Z$ ratios because $M Z$ and $D Z$ tetrachoric correlations were not reported. ATR, Australian Twin Registry; MTRS, Minnesota Twin Registry; NAS-NRCTR, NAS-NRC Twin Registry of World War II Veterans; STR, Swedish Twin Registry; VETR, Vietnam Era Twin Registry; VTR, Virginia Twin Registry.

COMORBIDITY

The co-occurrence of two or more diseases in an individual or an excess of disease co-occurrence in a population.

\section{PHENOCOPY}

Describes the situation in which a phenotype of an environmental origin mimics a phenotype of a genetic origin.

GENOCOPY

Describes the situation in which a phenotype of a genetic origin mimics a phenotype of a different genetic origin.

PENETRANCE

The probability of expressing a phenotype that is determined by a genotype.

LOCUS-BASED LINKAGE The detection of locus-to-locus or locus-to-phenotype genetic linkage. This is generally accomplished by detecting a lack of meiotic recombination in families in which alleles at one locus are observed to be in coupling (co-transmitted) or repulsion (not co-transmitted) with alleles at a second locus.
Shared and unshared inheritance. The abuse of drugs is frequently associated with the abuse of other drugs ${ }^{16}$. COMORBIDITY between disorders poses the question of shared causation, which is being answered by genetic transmission and linkage studies and studies of the neurobiological basis of addiction. The genetic studies address the extent to which variation in liability of different diseases is shared or unshared. Briefly, this is done by evaluating whether the disease status of a proband is predictive of the risk of developing a different disease in a relative; for example, a twin. Genetic studies that cross-compare risks for two phenotypes in twins and other relative pairs indicate that some risk factors are substance-specific whereas others are shared between different substances (reviewed by Goldman and Bergen ${ }^{17}$ ). Alcoholism and nicotine addiction, for example, are both comorbid and cross-transmitted. Approximately $85 \%$ of alcoholics smoke. Some $50 \%$ of the genetic liability to nicotine dependence is shared with alcoholism, and $15 \%$ of the genetic liability to alcoholism is shared with nicotine dependence ${ }^{18}$. These findings are guiding investigators to study genes involved in neurobiologies that are common to diverse addictive agents; for example, the nicotinic receptor subunit genes that are gatekeepers for nicotine action ${ }^{19}$ are also modulated by ethanol ${ }^{20}$.

Although such cross-transmission studies have a unique ability to detect the effects of common aetiology, they have important limitations. For example, the within-family shared environment might be more important in influencing which drug is used compared with whether a person becomes addicted to the drug. It is also more difficult to detect crosstransmission of the rarer addictions than it is for common addictions such as alcoholism and nicotine dependence ${ }^{2,8}$. These observations could help to explain the high substance-specific heritability $(0.70)$ for heroin among Vietnam veterans ${ }^{21}$ compared with the Virginia registry, where rates of exposure were lower and heroin-specific heritability was not detected $^{22}$.

\section{Gene identification: positional cloning}

Because addictions are common, it is possible to assemble large family and population datasets. The US National Institute on Drug Abuse (NIDA) Genetics Consortium is assembling datasets that consist of DNA, clinical diagnoses and other information relevant to drug addictions, and will be made available in 2006. Part of the US National Institute on Alcohol Abuse and Alcoholism (NIAAA) Collaborative Study on the Genetics of Alcoholism (COGA) dataset is available. Because addictions are common, the relative risk $(\lambda$, which is the ratio of familial risk to population risk) is not high for any of them and large datasets are therefore required. PHENOCOPIES and GENOCOPIES, as well as non-PENETRANCE, are important problems for these diseases, and the role of protective alleles is significant. Therefore, it is generally as informative to evaluate phenotypically unaffected and discordant relative pairs as it is to study affected relative pairs. The high population prevalences have also made it relatively easier to carry out linkage analysis in environmentally and genetically homogeneous population isolates such as southwestern Native Americans ${ }^{23}$ and Finns ${ }^{24}$. Such studies can be extended to larger population-based datasets, such as the Icelandic population ${ }^{25}$, which has proved powerful for the genetic analysis of complex diseases ${ }^{26}$.

Whole-genome linkage analysis using moderately sized marker panels and LOCUS-BASED LINKAGE on families that are derived from the cosmopolitan population of the United States and from population isolates has yielded replicated linkages to chromosomal regions ${ }^{27}$, even when these studies have used heterogeneous definitions such as alcohol dependence ${ }^{23,28}$, antisocial alcoholism ${ }^{24}$ or alcoholism with depressive syndrome ${ }^{29}$. Whole-genome scans using the allele-based LINKAGE DISEQUILIBRIUM approach have been carried out for addictions ${ }^{30}$ using a relatively small panel of SNP markers. These studies will be further facilitated by the large arrays of markers that are available through the International HapMap Project. Around $1,000,000$ SNPs and their linkage disequilibrium relationships and allele frequencies in four populations are recorded in the HapMap database. This project allows the selection of informative panels of marker loci, as well as known and potential functional loci, for almost any gene. Various methods for large-scale genotyping, including array methods, allow markerintensive gene, region-based and whole-genome linkage disequilibrium studies to be carried out. In this regard, NIDA recently announced its sponsorship of a whole-genome linkage disequilibrium scan for addictions. 
A non-exhaustive list of convergences across studies includes the telomere of chromosome $11 \mathrm{p}$, which contains the dopamine receptor D4 (DRD4) gene and several other neurogenetic candidate genes. Another region, on chromosome 4q, contains the alcohol dehydrogenase $(\mathrm{ADH})$ gene cluster, whereas a chromosome $4 \mathrm{p}$ region near the centromere contains a $\gamma$-aminobutyric acid receptor $A\left(\mathrm{GABA}_{\mathrm{A}}\right)$ gene cluster.

The GABA receptor. GABA is the principal inhibitory neurotransmitter in the brain and $\mathrm{GABA}_{\mathrm{A}}$ receptormediated chloride currents into neurons are facilitated by alcohol and by BENZODIAZEPINE DRUGS, with which alcohol shows cross-tolerance. A series of mouse ethanol-related behaviours, including preference, withdrawal severity and sedation sensitivity, map to four QUANTITATIVE TRAIT LOCUS (QTL) regions at which $\mathrm{GABA}_{\mathrm{A}}$ receptor-gene complexes are located ${ }^{31}$. These gene complexes apparently originated from ancient duplications of chromosomes or chromosomal regions, because the order and orientation of subunit gene types are conserved. In the rat, the $\mathrm{GABA}_{\mathrm{A}} \alpha 6$ subunit gene Arg100Gln missense variant is associated with variation in ethanol and benzodiazepine sensitivity ${ }^{32}$. A human variant of GABA $\alpha 6$ (Pro385Ser), which is located in the chromosome 5 cluster, is also linked to sensitivity to alcohol ${ }^{33,34}$ and benzodiazepine $e^{35}$ in relatively small datasets. Low alcohol response or sensitivity is a heritable intermediate phenotype that is predictive of increased alcohol preference in rodents ${ }^{36}$ and alcoholism in humans ${ }^{37}$. Variation in human alcohol response and mouse alcohol sensitivity is mainly PHARMACODYNAMIC in origin, rather than metabolic (PHARMACOKINETIC), pointing to potential differences in receptors or signalling molecules that might function as gatekeepers. In humans, both the chromosome 4 (REFS 23,38) and chromosome 5 (REF. 39) clusters are implicated. Linkage disequilibrium mapping has refined the localization to the $\mathrm{GABA}_{\mathrm{A}} \alpha 6$ region $^{39}$ on chromosome 5 and the $\mathrm{GABA}_{\mathrm{A}} \alpha 2$ gene region ${ }^{38}$ on chromosome 4 (FIG. 5).

Alcohol dehydrogenase genes. The two outstanding examples of verified human 'addiction genes' encode for enzymes that catalyse consecutive steps in alcohol metabolism: alcohol dehydrogenase IB $(A D H 1 B)$ and aldehyde dehydrogenase $2(A L D H 2)$. ADH metabolizes ethanol to acetaldehyde, a toxic intermediate, which is in turn converted to acetate by ALDH. The most important functional loci at these genes are His 47Arg in the $A D H 1 B$ gene and Glu487Lys in the $A L D H 2$ gene. Either higher activity of ADH1B (conferred by the His 47 allele) or lower activity of ALDH2 (conferred by the Lys 487 allele) leads to accumulation of acetaldehyde following an alcohol load. Acetaldehyde accumulation causes the aversive flushing reaction that discourages further alcohol intake. The genotype-associated flushing that is attributable to the higher activity codominant His 47 allele and the lower activity dominant Lys 487 allele is equivalent to
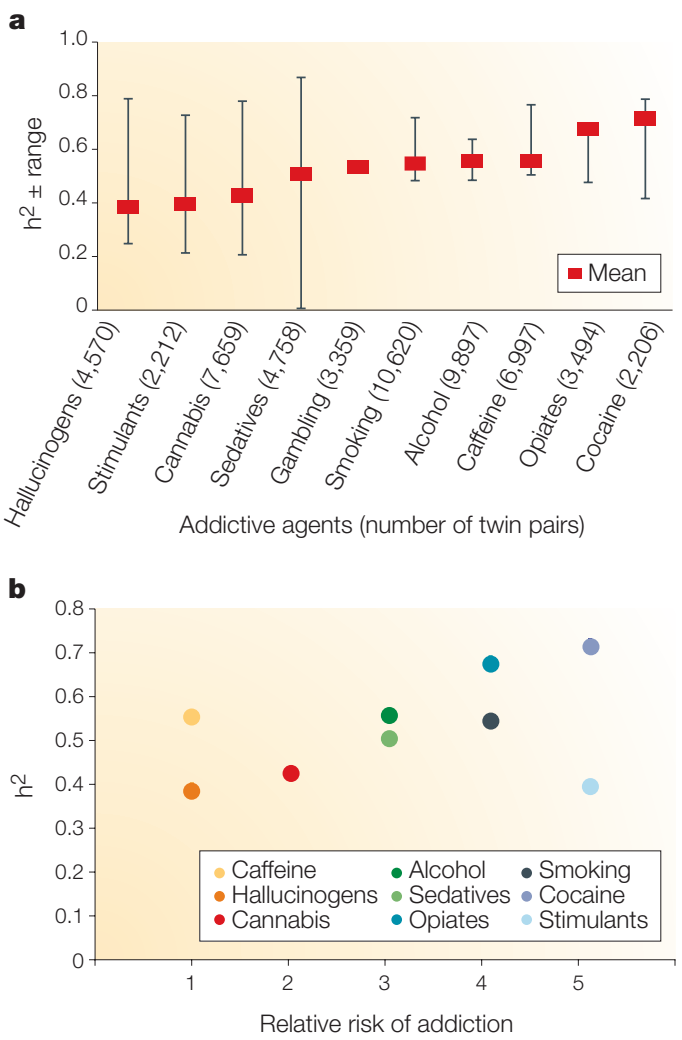

Figure 2 | Heritability of addictive disorders. a | The heritability (weighted mean and range) of 10 addictive disorders. These include hallucinogens, stimulants, cannabis, sedatives, gambling, smoking persistence, alcohol dependence, caffeine consumption or heavy use, cocaine dependence or abuse, and opiates. b | Weighted heritability $\left(h^{2}\right)$ is plotted against the approximate ranking for relative risk of addiction. Relative risk of addiction is expressed on a five-point scale ${ }^{14}$, one indicates the lowest risk and five denotes the highest risk. In parts $\mathbf{a}$ and $\mathbf{b}$, $\mathrm{h}^{2}$ means were calculated using data from the national surveys of adult twins listed in TABLE 1.

the effects of disulfiram (a drug that is used to prevent relapse), and to certain antiprotozoal drugs, such as metronidazole, that inhibit ALDH. In several eastern Asian countries, such as Japan, where both His 47 and Lys 487 are highly abundant, most of the population carries a heterozygous or homozygous genotype that is protective against alcoholism. The protective effect seems to vary across environments ${ }^{40}$ and the effects of genotypes are additive ${ }^{41}$. Each of these protective alleles apparently represents a single ancient mutation ${ }^{42-45}$, based on the highly diverged haplotypes on which they reside, and there is some haplotype-based evidence for maintenance by selection ${ }^{42}$. It is improbable that these gene variants have evolved to protect against alcoholism. It is more plausible that these common gene variants might have conferred some other effect on fitness, such as protection against severe infectious diseases by protozoans that are sensitive to inhibition of alcohol metabolism, either because of their localization in the gut or because of their lack of intrinsic aldehyde dehydrogenase ${ }^{46}$. 
a

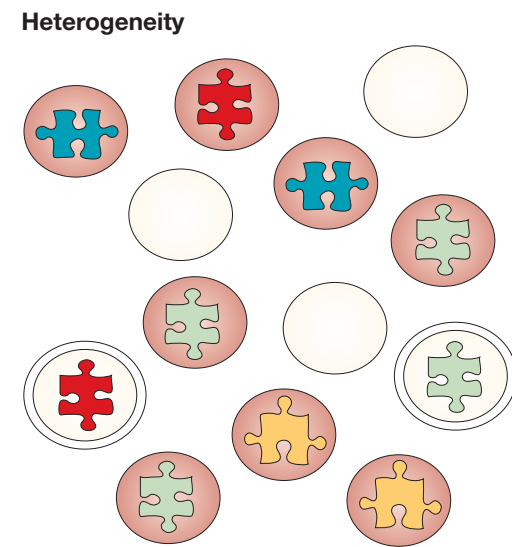

Different risk alleles individually produce the same phenotype

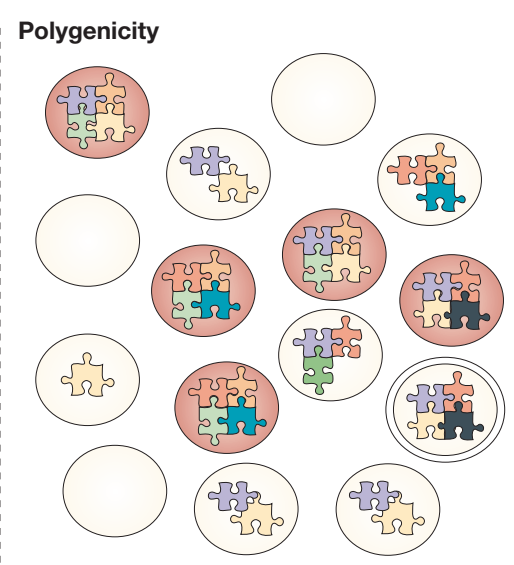

Combinations of risk alleles are required to produce a phenotype

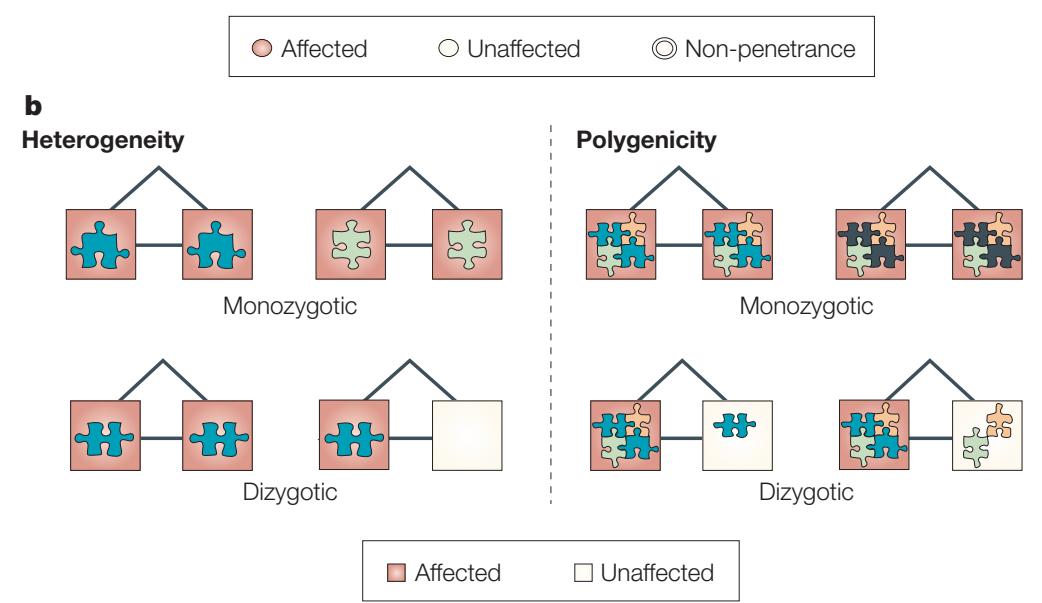

Figure $3 \mid$ Genetic complexity in unrelated individuals and its effect on twin concordance. a | Genetic complexity in unrelated individuals. b | Genetic complexity in twin pairs. Each risk allele is represented as a puzzle piece of a different colour or shape.

MANIA

A pathological elevated

mood-state that is associated

with mental and physical

hyperactivity.

PANIC DISORDER

An anxiety disorder

characterized by paroxysms of

overwhelming fear with

associated somatic, behavioural

and cognitive symptoms.

AGORAPHOBIA

An anxiety disorder that is

characterized by fear and

avoidance of places from which

escape might be difficult.

Our understanding of the neurobiological basis of addiction has evolved mainly from studies in animal models (BOX 3). The potential uses of animal models are almost limitless owing to the ability to directly access addiction neurobiology and the new and emerging tools to selectively express and downregulate genes in different regions of the brain. As genetic variants that are orthologous to human polymorphisms are discovered, sequencing of mouse, rat and non-human primate genomes is allowing these species to be better exploited.

\section{Progress through intermediate phenotypes}

The neurobiological processes that are involved in addiction, including reward, executive cognitive function and stress or anxiety, substantially overlap with those that underlie other psychiatric disorders, leading to the expectation that shared genetic factors are involved. Therefore, it is crucial to determine whether common disease origins determine the excess aggregation of these disorders observed in populations and in families ${ }^{2,16,47,48}$. Such aggregation can be due to the natural course of one disease increasing the risk of developing a second disease or because individuals who are chronic, treatment resistant or psychosocially impaired are more likely to be ascertained ${ }^{49}$. Several loci that alter intermediate phenotypes that are important in shared risk have been found (see below). Intermediate phenotypes that reflect substance-specific neurobiology have been identified - for example, variation in alcohol-induced sedation and euphoria - and are also being used to identify genes that might be substance-specific in their action ${ }^{34}$.

Impulsivity and externalizing behaviours. Behavioural control is fundamental for the ability to inhibit the immediate pursuit of pleasurable stimuli and for the development of structured patterns of behaviour that produce long-term rewards. In children, deficits in the development of behavioural control lead to various problems, including substance use $e^{50,51}$. In the Virginia Twin cohort, a common factor encompassing externalizing disorders such as antisocial personality disorder (ASPD) and conduct disorder (CD) accounted for $71 \%$ of the genetic liability to alcoholism and $67 \%$ of the inheritance of vulnerability to illicit drug abuse or dependence ${ }^{5}$. Data from other twin studies, including a large community sample ${ }^{52}$ and a small sample of $\mathrm{MZ}$ twins that were reared apart ${ }^{53}$, also revealed the connection between ASPD, CD and alcoholism. In a seminal adoption study, antisocial personality and alcoholism were observed to be cross-inherited ${ }^{54}$. The temporal sequence is consistent with the hypothesis that antisocial behaviours and CD are causal factors for alcoholism and other substance dependencies, because CD usually occurs before alcohol dependence. However, alcohol and other drugs are disinhibiting, leading to antisocial behaviours ${ }^{55}$. In adolescence, the likelihood of alcoholism and drug abuse is diminished by $4-5 \%$ for each year that onset of drug use is delayed ${ }^{56}$.

Several genes that influence impulsivity and externalization have been found. Polymorphisms in both the DRD4 gene and the dopamine transporter SLC6A3 (solute carrier family 6, member 3 ) have been linked to attention deficit hyperactivity disorder (ADHD) and $\mathrm{CD}$, with linkage to $\mathrm{DRD} 4$ long-repeat alleles being more replicable ${ }^{57}$. Monoamine oxidase A (MAOA) metabolizes dopamine and a rare stop-codon variant of this gene was linked to impulsive behaviour among males in a Dutch family ${ }^{58}$. An abundant MAOA variable number tandem repeat locus is linked to antisocial behaviour in children, in an environment-specific fashion $^{59}$. Serotonin is the neurotransmitter that is most consistently implicated in aggression and impulsivity by neurochemical and neurobehavioural studies in humans and other species ${ }^{55}$. The 5-hydroxytryptamine (serotonin) receptor $1 \mathrm{~B}(H T R 1 B)$ gene is located at the site of several mouse alcohol QTLs on chromosome 9, and mice in which this gene has been knocked out were more aggressive and had a preference for alcohol $^{60}$. HTR1B was linked to 'antisocial alcoholism' in a Finnish family sample that was ascertained through criminal alcoholic probands, and in a southwestern Native American community sample ${ }^{24}$. However, replication of the association of $H T R 1 B$ with impulsivity 


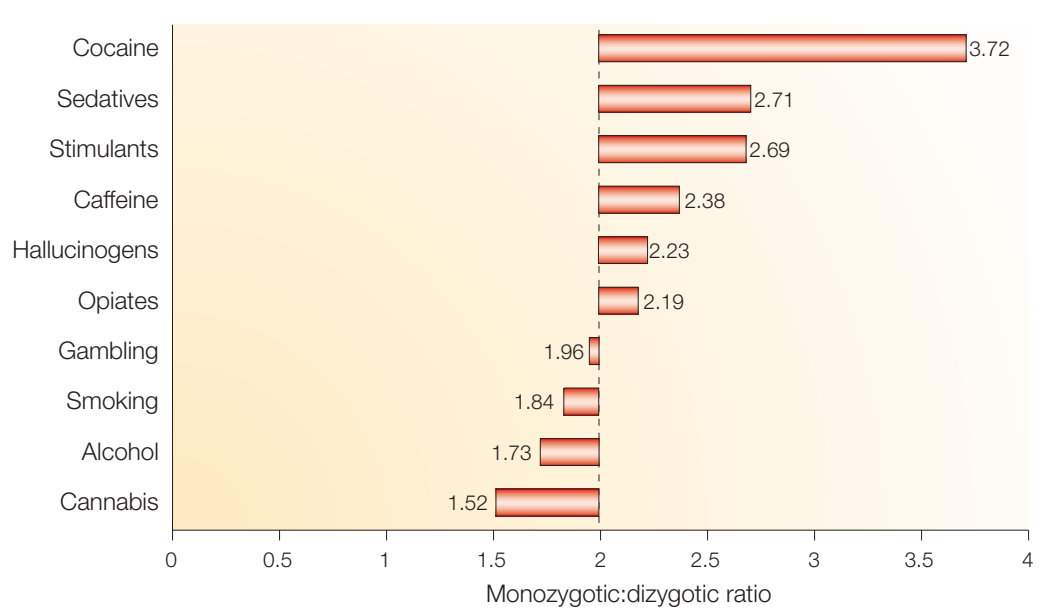

Figure 4 | Weighted means of monozygotic and dizygotic tetrachoric correlation ratios for 10 addictive disorders. Weighted means of monozygotic to dizygotic ratios were calculated using monozygotic and dizygotic tetrachoric correlations that were estimated from the national surveys of adult twins listed in TABLE 1 . The dashed line indicates the 2:1 ratio that is expected for a monogenic dominantly inherited phenotype.

\section{BULIMIA}

An eating disorder that is characterized by recurrent binge eating, which is accompanied by self-induced purging and/or other inappropriate compensatory behaviours.

\section{ALLOSTASIS}

A new homeostatic (maintained) equilibrium that lies outside the normal range and is characterized by long-lasting adaptational mechanisms that are activated in response to a stressor.

\section{CATECHOLAMINES}

A class of structurally similar amine neurotransmitters, including dopamine, noradrenaline and adrenaline, that are derived from the amino acid tyrosine.

WISCONSIN CARD-SORT TEST A neurocognitive test of frontal lobe function that requires the subject to switch strategies that are needed to match cards to a target.

\section{N-BACK TEST}

A neurocognitive test of frontal lobe function and working memory that requires the recall of an earlier stimulus after a new stimulus (or stimuli) has been presented.

WORKING MEMORY

A memory system that is activated for temporary storage and manipulation of information while a mental task is carried out. or aggression has been variable ${ }^{61,62}$ and no functional locus polymorphism is known.

Intermediate phenotypes in impulsivity and externalization have been linked to certain gene regions, and to specific loci. Disturbed attention processes, as assessed by electrophysiological responses to unexpected stimuli, are more common in drug-naive offspring of alcoholics. The use of this phenotype in a whole-genome linkage scan led to the identification of several linkage regions ${ }^{63}$. The chromosome $11 \mathrm{p}$ telomere region has been linked to addictions ${ }^{36}$. DRD4 lies on chromosome 11p, and a 16 amino-acid repeat polymorphism in DRD4 has variably been associated with novelty seeking ${ }^{64,65}$.

The anxiety or dysphoria domain. In the NESARC national epidemiologic survey, all mood and anxiety disorders were comorbid with alcohol and druguse disorders (odds range from 1.6 to 13.9), the strongest correlation being between MANIA and PANIC DISORDER, and AGORAPHOBIA $^{2}$. The magnitude of anxiety and addiction comorbidity is greater in women ${ }^{48}$. Large twin studies ${ }^{5,66}$ provide only weak support for a shared genetic predisposition to substance-use disorders and the mood and anxiety disorders. In a study on females, more than three-quarters of the genetic liability to alcoholism was not shared with major depression, anxiety disorders and BULIMIA ${ }^{66}$. In both men and women, alcoholism and other drug disorders are genetically largely independent from major depression, generalized anxiety and phobic disorders ${ }^{5}$. However, fundamental to the process of addiction is a drug exposure-induced shift to a long-lasting ALLOSTATIC state such that many drug-free addicts show persistent affective disturbances and are vulnerable to craving. This means that they are liable to rapid relapse when triggered by stressful life events or re-exposure to the drug. When re-administered, the drug might elevate mood, but not to the level experienced before addiction ${ }^{67}$. Studies on drug-exposed animals indicate that long-lasting physiological changes take place that are associated with changes in the expression of stress-related genes ${ }^{68,69}$. It is likely that individuals are predisposed to addiction, based on diminished stress resiliency ${ }^{69}$. Indeed, acute and early-life stress exposures have the effect of increasing the risk of addictions and other psychiatric diseases ${ }^{70}$ and of increasing the intake of alcohol and drugs in animal models ${ }^{71}$.

\section{Genes and neurobiologies}

Vulnerabilities to substance use diverge diametrically between individuals; this fact provides an opportunity and a challenge for gene mapping. The catechol-Omethyltransferase (COMT) gene provides a powerful example. COMT is an enzyme that metabolizes CATECHOLAMINES, terminating the action of these neurotransmitters in the synapse, particularly in regions of the brain where levels of the relevant monoamine transporters are low. A common polymorphism that exerts an effect on COMT function is Val158Met. The Val158 allele is approximately three times more thermostable than Met158 at normal body temperature, and has $40 \%$ higher activity ${ }^{72}$. Furthermore, Val158 and Met158 are found on differentially expressed haplotype backgrounds $\mathrm{s}^{73}$ of ancient origin, as indicated by their opposite (yin-yang) allelic configurations (a 5-locus haplotype pattern of 1122 Val versus $2211 \mathrm{Met}$ ) that are both abundant in populations worldwide ${ }^{74}$. The haplotype analyses predict variation in COMT expression, and it is likely that COMT linkage studies will incorporate haplotype information to capture more details on the functional genetic variation of this gene. For example, linkage of a Val158-containing haplotype to schizophrenia was more robust than the Val158 allele itself ${ }^{75}$, and haplotype analysis was also used in a replication study of linkage of COMT to pain threshold ${ }^{76}$.

The higher activity Val158 allele is predicted to reduce dopamine levels in the frontal cortex because levels of the dopamine transporter are low in this region. Consistent with the role of dopamine in the tuning of frontal cortical function, the Val158 allele and Val158 haplotypes have replicably been linked to frontal lobe function, as assessed by measures such as the WISCONSIN CARD-SORT TEST and the N-BACK TEST ${ }^{77-79}$, and by the metabolic activity of the frontal cortex during a WORKING-MEMORY task $k^{77}$. In certain populations, including polysubstance abusers that were ascertained in Baltimore, $\mathrm{USA}^{80}$, the Val158 allele is associated with vulnerability to addiction through impulsivity or dyscontrol. By contrast, in populations of addicts in whom anxiety is a more salient predisposing cause - for example, in late-onset alcoholics $^{81}$ and social drinkers ${ }^{82}$ - the Met158 allele is more common. The counterbalancing disadvantage (in fitness terms) of the Met158 allele seems to be the enhanced vulnerability of Met158 genotypes to stress and anxiety. Met158 homozygous women in two different populations were more anxious ${ }^{83}$. This balance of advantages in stress resiliency (Val158 allele) versus 


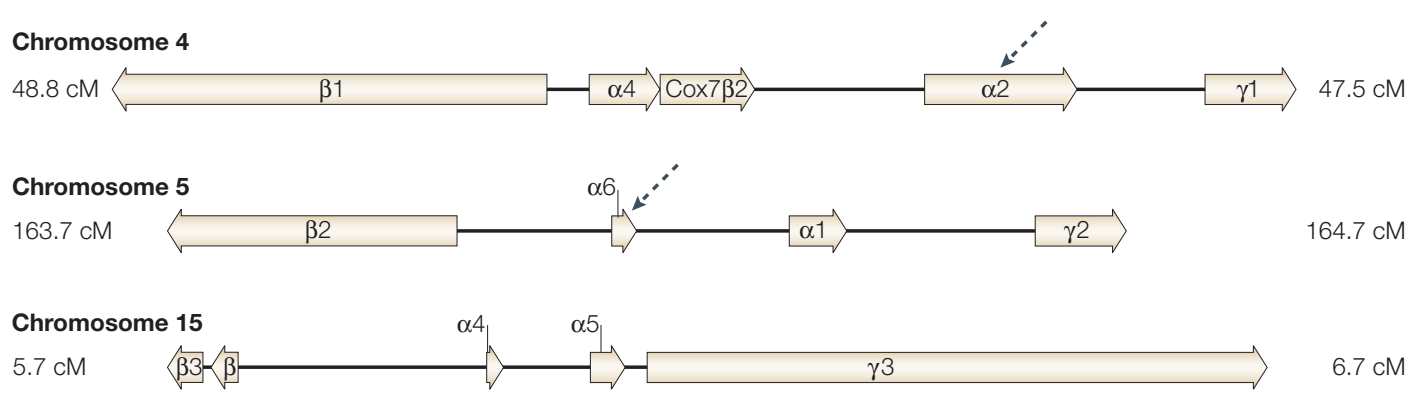

Figure 5 | Clusters of the $\gamma$-aminobutyric acid (GABA) subunit genes in humans. Arrows indicate chromosome regions that have been shown to influence vulnerability to alcoholism in the pharmacodynamic domain.

cognitive function (Met158 allele) forms the basis for the WARRIOR/WORRIER MODEL. This model invokes frequency-dependent selection or balancing selection to conserve both ancient COMT functional alleles across human populations. The warrior haplotype (Val158) leads to better stress resiliency, but also to modest diminution of executive cognitive performance under most conditions. On the other hand, following a pain or stress challenge, the worrier (Met158) allele dosage predicted a progressively lower pain threshold, stronger affective response to pain and inability of the endogenous brain opioid system to become activated following pain ${ }^{84}$. As already mentioned, linkage of Met haplotypes to a lower threshold to experimentally administered painful stimuli was recently replicated in a large cohort of women ${ }^{76}$.

Linkage studies of the serotonin transporter gene underline the power of neuroimaging studies and the usefulness of approaches that consider the interaction of environmental and gene effects. Two main alleles of the serotonin transporter polymorphism (HTTLPR) that lie in the promoter of this gene have either 14 (short (S)) or 16 (long (L)) copies of a 22-bp imperfect repeat ${ }^{85}$. The lower transcribing $S$ allele contributes significantly to risk for alcohol dependence, with the greatest effect observed among individuals with more severe alcohol dependence, antisocial behaviour or suicide attempt ${ }^{86}$. However, this locus only has a modest effect on complex behaviour. The $\mathrm{S}$ allele has been linked to anxiety, but in a meta-analysis of 23 association studies, each copy of the $S$ allele contributed only a 0.106 standard deviation increment in anxiety that was measured on personality scales ${ }^{87}$. Furthermore, without objectively discarding certain studies there was no significant effect overall ${ }^{87}$.

The role of the serotonin transporter in behaviour has been clarified by studies showing that the effect of the $\mathrm{S}$ allele in dysphoria and drug consumption might be dependent on exposure to stress ${ }^{71,88}$. The effects of this locus are clearest at the neurobiological level. The polymorphism alters transporter expression in the brain ${ }^{89,90}$ and in the AMYGDALA, and changes the metabolic response to emotional stimuli ${ }^{91}$ and the volume of the amygdala ${ }^{92}$. Recently, the additive effects of HTTLPR alleles and COMT Val158Met allele were observed in the metabolic response of the amygdala to emotional stimuli ${ }^{93}$. A further functional allele was also discovered at the HTTLPR locus (an A to $G$ substitution in the first of the two extra repeats defining the $\mathrm{L}$ allele) ${ }^{94}$, which accounts for even more variation in serotonin transporter expression, and improves the ability to predict both complex behaviours and intermediate phenotypes ${ }^{95}$.

\section{From genotype to medical management}

The treatment and prevention of addictions are only partially successful. Prevention strategies could focus on children and adults who are vulnerable due to variations in particular neurobiological domains, for example, behavioural dyscontrol versus stress or anxiety. It is still unclear whether such targeting of prevention would be essential or even appropriate. The high rates of addictions and the economics of the problem make it worthwhile to apply many prevention strategies across entire population cohorts without identifying particular vulnerability alleles. However, it would be important to know the efficacy (or lack of effect) of untargeted prevention strategies on individuals with particular vulnerabilities.

Individualization of therapy and the identification of new therapeutic targets are required for the large number of individuals who are already ill, and for the newly incident cases each year. One-year relapse rates for alcoholism and cocaine range from 20 to $60 \%$, depending on the clinical study ${ }^{96,97}$. Medications for treatment of addictions include AGONISTS (methadone), ANTAGONISTS (naltrexone), anticraving medications and drugs that block the metabolism ${ }^{98}$. Except for the management of the acute phase, addictions remain largely under-treated diseases. Although addictions are chronic and relapsing or remitting, medical management has focused on the acute phase (intoxication and withdrawal) because treatment occurs within a socio-medical matrix in which long-term benefits of prevention and follow-up care are not encouraged by adequate reimbursement ${ }^{98}$. This is despite the efficacy of treatment, which is comparable to that of treatment for other chronic disorders such as diabetes and asthma ${ }^{98}$. For such illnesses, incremental improvements in management that are applied conscientiously have extended life expectancies from less than 20 years to more than 50 years. Improvements in the targeting of addiction treatment and availability of new treatment methods (including new approaches to cognitive and behavioural therapy) could also drive 


\section{Box 3 | Animal models of addiction neurobiology and genetics}

Studies in rodents have identified both neuroanatomical circuits ${ }^{112}$ (such as limbic reward and emotionality circuits) and cellular molecular networks that are crucial in addiction ${ }^{113,114}$. Several of the genes that are central to drug response and neuroadaptation have already been tested as leading candidates in genetic studies in humans. So far, the brain-derived neurotrophic factor $(B D N F)^{115}$, the 5-hydroxytryptamine (serotonin) receptor $1 \mathrm{~B}(H T R 1 B)^{24}$, the $\gamma$-aminobutyric acid receptor $\mathrm{A}\left(\mathrm{GABA}_{\mathrm{A}}\right)$ receptor $^{38}$, neuropeptide $\mathrm{Y}(N P Y)^{116}$, and the dopamine $\mathrm{D} 2$ receptor $(D R D 2)^{117}$ genes have been implicated in animal studies and evaluated in humans, with promising results. However, most of the strong candidate genes to emerge from animal neurobiological studies of addiction have yet to be evaluated for sequence variation and linkage to human addictive behaviour. These include deltaFos $B$, and the genes that encode the proline-cysteine transporter, the cyclic-AMP-response element binding protein (CREB), and various glutamate receptors ${ }^{113,114}$.

Animal models allow genes to be associated with neurobiological phenotypes that are not accessible in humans, and with various addiction-related behaviours that are studied under highly controlled conditions. In rodents, genes that are implicated by QTL studies include the $\mu$-opioid receptor 1 (OPRM1) in morphine preference ${ }^{118,119}$, the multiple PDZ-binding domain protein $(M P D Z)$ in acute pentobarbital and ethanol withdrawal ${ }^{120}, N P Y$ in ethanol preference ${ }^{121}$, glutamic acid decarboxylase (GAD1), a GABA biosynthetic enzyme, in ethanol-induced locomotion ${ }^{122}$, and $D R D 2$ and HTR1B in ethanol preference ${ }^{31}$. The functional allele has not been verified in any of these cases, but in other examples, effects of alleles, including artificial gene knockouts, are directly known. Cheapdate, a mutation that leads to enhanced sensitivity to ethanol in Drosophila melanogaster, is an allele of the memory mutant Amnesiac and results in diminished activation of the cAMP pathway ${ }^{123}$. In primates, a serotonin transporter promoter locus that is orthologous to a functional polymorphism in the promoter of a human serotonin transporter alters ethanol preference, and this effect can be modified by stress in early life ${ }^{71}$. More than 100 mouse gene knockouts and transgenics alter addiction-related behaviours, reflecting the diversity of pathways that can lead to addiction, and the potential for heterogeneity or polygenicity discussed earlier. OPRM1 mouse knockouts are characterized by reduced opioid-mediated analgesia, reward and physical dependence ${ }^{124}$. The knockout for the nicotinic acetylcholine receptor $\beta 2$ gene blocks nicotine self-administration, reflecting the gatekeeper role of the nicotinic receptor in influencing the self-administration of this drug ${ }^{125}$. Knockouts in signalling genes such as protein kinase $\mathrm{C}(P K C)^{126}$ or genes that modulate stress response, such as $N P Y^{127}$, could be predicted to influence diverse addictive behaviours.

changes in the clinical management of these diseases, leading to a more multidimensional level of care. The clinical subclassifications of addictive disorders are a first systematic effort to create more homogeneous categories to individualize treatment and prevention, and to identify new therapeutic targets. It is precisely at this point that progress has stalled. Although some drugs (for example, naltrexone and acamprosate) have efficacy for the treatment of heterogeneous populations of alcoholics, others (for example, ondansetron and selective serotonin reuptake inhibitors) seem to be differentially effective in subgroups ${ }^{99-101}$. However, although efforts to clinically subclassify addictions are likely to continue, it is improbable that future meta-groupings of addictions and other psychiatric diseases will advance until neurobiological indicators, including genotypes, are integrated.

\section{Conclusions}

Liability to addictions is widespread, but individuals with addicted first-degree relatives are at greater risk. The correlation between the heritability of different addictions and the relatively simple estimates of addiction liability for particular agents indicates that a large component of what is inherited is interindividual variation in the fundamental neurobiological basis of addiction. Advances in the neurobiology of addiction have led to the identification of some underlying genes and have allowed the actions of certain risk loci to be understood. Genetic loci that have defined roles in addictions include substance-specific genes, such as the alcohol metabolic genes, and loci, such as the serotonin transporter and COMT, that alter liability to different addictions and other psychiatric illnesses. Evidence from twin studies indicates that further loci in both addiction substance-specific and addiction substance-nonspecific categories will be discovered. The twin concordance ratio data predict that many of the addiction loci will have an individual effect whenever the functional allele is actually found in a person. This information helps us to postulate that genetic markers with significant predictive value will be discovered and serve as guides to new molecular mechanisms and targets for medicine.

Large datasets and new tools in genetics and molecular neurobiology have facilitated various genetic approaches in humans and other species. These approaches have allowed the detection of gene effects on the clinical phenotypes of addictions that are small on a population basis and that, because of causal heterogeneity, are sometimes inconsistent across different types of addicted patient. Larger and apparently more consistent gene effects are being observed at the levels of neurobiology and of intermediate phenotypes, and owing to the improved understanding of the influence of environmental exposures, particularly stress. Indeed, identifying gene-environment interactions is a crucial issue in the study of addictions, which by definition depend on exposure to an addictive agent and are strongly modulated by other environmental factors. The story of genes in addictions and other complex behavioural 
diseases seems to be one of incremental progress as the functional significance of sequence variations is discovered and then related both to intermediate phenotypes and to the complex diseases that are emergent from an intermediate neurobiology.

The high population prevalences of addictions and the relative crudity and ineffectiveness of addiction treatment and management constitute a public-health crisis. Through intensive clinical management and the application of new strategies, the outcomes of other chronic medical diseases such as cystic fibrosis ${ }^{102}$ and juvenile-onset diabetes ${ }^{103}$ have been markedly improved. There is no indication that such comprehensive approaches are on the verge of being developed and applied to the addictions without significant breakthroughs in genetics and neurobiology. It is a sobering reality that genetic findings have so far not led to the creation or targeting of addiction treatment or prevention. Future research is likely to integrate genetic variation ever more closely, with effects on intermediate neurobiological processes such as reward, behavioural control and anxiety response that are now understood to underlie addiction vulnerability and recovery. Such studies will frequently be fine-grained and take advantage of powerful methods that capture neurobiology, including neuroimaging, and direct interventional studies in animals that are not feasible, or ethical, in humans. Future research must also find a role for genotypes, either as guides to new therapeutic targets or as predictors for treatment and prevention, in natural populations of patients and individuals at risk where the efficacy of new tools can objectively be defined and integrated into multidimensional management.
1. Roberts, A. J. \& Koob, G. F. The neurobiology of addiction: an overview. Alcohol Health Res. World 21, 101-106 (1997).

2. Grant, B. F. et al. Prevalence and co-occurrence of substance use disorders and independent mood and anxiety disorders: results from the National Epidemiologic Survey on Alcohol and Related Conditions. Arch. Gen. Psychiatry 61, 807-816 (2004).

3. McGinnis, J. M. \& Foege, W. H. Mortality and morbidity attributable to use of addictive substances in the United States. Proc. Assoc. Am. Physicians 111, 109-118 (1999).

4. Merikangas, K. R. \& Risch, N. Genomic priorities and public health. Science 302, 599-601 (2003).

5. Kendler, K. S., Prescott, C. A., Myers, J. \& Neale, M. C. The structure of genetic and environmental risk factors for common psychiatric and substance use disorders in men and women. Arch. Gen. Psychiatry 60, 929-937 (2003)

Presents an explanation for the origin of comorbidity between substance-use disorders and other psychiatric disorders.

6. Krueger, R. F. et al. Etiologic connections among substance dependence, antisocial behavior, and personality: modeling the externalizing spectrum. J. Abnorm. Psychol. 111, 411-424 (2002).

7. Young, S. E., Stallings, M. C., Corley, R. P., Krauter, K. S. \& Hewitt, J. K. Genetic and environmental influences on behavioral disinhibition. Am. J. Med. Genet. 96, 684-695 (2000).

8. Grant, B. F., Hasin, D. S., Chou, S. P., Stinson, F. S. \& Dawson, D. A. Nicotine dependence and psychiatric disorders in the United States: results from the national epidemiologic survey on alcohol and related conditions. Arch. Gen. Psychiatry 61, 1107-1115 (2004).

9. Vega, W. A. et al. Prevalence and age of onset for drug use in seven international sites: results from the international consortium of psychiatric epidemiology. Drug Alcohol Depend. 68, 285-297 (2002).

10. Reuter, J. et al. Pathological gambling is linked to reduced activation of the mesolimbic reward system. Nature Neurosci. 8, 147-148 (2005).

11. Hasin, D. Classification of alcohol use disorders. Alcohol Res. Health 27, 5-17 (2003).

12. Li, M. D., Cheng, R., Ma, J. Z. \& Swan, G. E. A meta-analysis of estimated genetic and environmental effects on smoking behavior in male and female adult twins. Addiction 98, 23-31 (2003).

13. Kendler, K. S., Karkowski, L. M., Neale, M. C. \& Prescott, C. A. Illicit psychoactive substance use, heavy use, abuse, and dependence in a US population-based sample of male twins. Arch. Gen. Psychiatry 57, 261-269 (2000).

14. Goldstein, A. \& Kalant, H. Drug policy: striking the right balance. Science 249, 1513-1521 (1990). Discusses the advantages and pitfalls of drug legalization.

15. Merikangas, K. R. \& Avenevoli, S. Implications of genetic epidemiology for the prevention of substance use disorders. Addict. Behav. 25, 807-820 (2000).

16. Kessler, R. C. et al. Lifetime co-occurrence of DSM-III-R alcohol abuse and dependence with other psychiatric disorders in the National Comorbidity Survey. Arch. Gen. Psychiatry 54, 313-321 (1997).
17. Goldman, D. \& Bergen, A. General and specific inheritance of substance abuse and alcoholism. Arch. Gen. Psychiatry 55, 964-965 (1998).

An overview of the general and specific inheritance of different addictions.

18. Swan, G. E., Carmelli, D. \& Cardon, L. R. Heavy consumption of cigarettes, alcohol and coffee in male twins. J. Stud. Alcohol 58, 182-190 (1997).

19. Picciotto, M. R. \& Corrigall, W. A. Neuronal systems underlying behaviors related to nicotine addiction: neural circuits and molecular genetics. J. Neurosci. 22 , 3338-3341 (2002).

20. Yu, D. et al. Ethanol inhibition of nicotinic acetylcholine type $\alpha 7$ receptors involves the amino-terminal domain of the receptor. Mol. Pharmacol. 50, 1010-1016 (1996).

21. Tsuang, M. T. et al. Co-occurrence of abuse of different drugs in men: the role of drug-specific and shared vulnerabilities. Arch. Gen. Psychiatry 55, 967-972 (1998).

22. Kendler, K. S., Jacobson, K. C., Prescott, C. A. \& Neale, M. C. Specificity of genetic and environmental risk factors for use and abuse/dependence of cannabis, cocaine, hallucinogens, sedatives, stimulants, and opiates in male twins. Am. J. Psychiatry 160, 687-695 (2003).

23. Long, J. C. et al. Evidence for genetic linkage to alcohol dependence on chromosomes 4 and 11 from an autosome-wide scan in an American Indian population. Am. J. Med. Genet. 81, 216-221 (1998).

24. Lappalainen, J. et al. Linkage of antisocial alcoholism to the serotonin 5- $\mathrm{HT}_{1 \mathrm{~B}}$ receptor gene in 2 populations. Arch. Gen. Psychiatry 55, 989-994 (1998)

25. Thorgeirsson, T. E. et al. Anxiety with panic disorder linked to chromosome 9q in Iceland. Am. J. Hum. Genet. 72 1221-1230 (2003).

26. Hennah, W., Varilo, T., Paunio, T. \& Peltonen, L. Haplotype analysis and identification of genes for a complex trait: examples from schizophrenia. Ann. Med. 36, 322-331 (2004).

27. Uhl, G. R. Molecular genetics of substance abuse vulnerability: remarkable recent convergence of genome scan results. Ann. NY Acad. Sci. 1025, 1-13 (2004).

An overview of converging results from genome scans for various addictions.

28. Reich, T. et al. Genome-wide search for genes affecting the risk for alcohol dependence. Am. J. Med. Genet. 81 207-215 (1998).

29. Nurnberger, J. I. Jr et al. Evidence for a locus on chromosome 1 that influences vulnerability to alcoholism and affective disorder. Am. J. Psychiatry 158, 718-724 (2001).

30. Uhl, G. R., Liu, Q. R., Walther, D., Hess, J. \& Naiman, D. Polysubstance abuse-vulnerability genes: genome scans for association, using 1,004 subjects and 1,494 singlenucleotide polymorphisms. Am. J. Hum. Genet. 69, 1290-300 (2001).

31. Crabbe, J. C., Phillips, T. J., Buck, K. J., Cunningham, C. L. \& Belknap, J. K. Identifying genes for alcohol and drug sensitivity: recent progress and future directions. Trends Neurosci. 22, 173-179 (1999).
32. Korpi, E. R., Kleingoor, C., Kettenmann, H. \& Seeburg, P. H. Benzodiazepine-induced motor impairment linked to point mutation in cerebellar $\mathrm{GABA}_{\mathrm{A}}$ receptor. Nature 361, 356-359 (1993).

33. $\mathrm{Hu}, \mathrm{X}$. et al. An expanded evaluation of the relationship of four alleles to the level of response to alcohol and the alcoholism risk. Alcohol Clin. Exp. Res. 29, 8-16 (2005).

34. Schuckit, M. A. et al. Selective genotyping for the role of $5-\mathrm{HT}_{2 \mathrm{~A}}, 5-\mathrm{HT}_{2 \mathrm{C}}$, and GABA $\alpha 6$ receptors and the serotonin transporter in the level of response to alcohol: a pilot study. Biol. Psychiatry 45, 647-651 (1999).

35. Iwata, N., Cowley, D. S., Radel, M., Roy-Byrne, P. P. \& Goldman, D. Relationship between a GABA $\alpha 66$ Pro385Ser substitution and benzodiazepine sensitivity. Am. J. Psychiatry 156, 1447-1449 (1999).

36. Fee, J. R. et al. Predictors of high ethanol consumption in RII $\beta$ knock-out mice: assessment of anxiety and ethanolinduced sedation. Alcohol. Clin. Exp. Res. 28, 1459-1468 (2004).

37. Schuckit, M. A. \& Smith, T. L. An 8-year follow-up of 450 sons of alcoholic and control subjects. Arch. Gen. Psychiatry 53, 202-210 (1996).

38. Edenberg. H. J. et al. Variations in GABRA2, encoding the $\alpha 2$ subunit of the GABA, receptor, are associated with alcohol dependence and with brain oscillations. Am. J. Hum. Genet. 74, 705-714 (2004).

39. Radel, M. et al. Haplotype-based localization of an alcohol dependence gene to the $5 q 34 \gamma$-aminobutyric acid type A gene cluster. Arch. Gen. Psychiatry 62, 47-55 (2005).

40. Tu, G. C. \& Israel, Y. Alcohol consumption by orientals in North America is predicted largely by a single gene. Behav. Genet. 25, 59-65 (1995).

41. Thomasson, H. R. et al. Alcohol and aldehyde dehydrogenase genotypes and alcoholism in Chinese men. Am. J. Hum. Genet. 48, 677-681 (1991).

Shows that functional polymorphisms in $A D H 1 B$ and $A L D H 2$ function additively to modify the risk of alcoholism by inducing the flushing response.

42. Peterson, R. J., Goldman, D. \& Long, J. C. Effects of worldwide population subdivision on ALDH2 linkage disequilibrium. Genome Res. 9, 844-852 (1999).

43. Peterson, R. J., Goldman, D. \& Long, J. C. Nucleotide sequence diversity in non-coding regions of $\mathrm{ALDH} 2$ as revealed by restriction enzyme and SSCP analysis. Hum. Genet. 104, 177-187 (1999).

44. Oota, H. et al. The evolution and population genetics of the $A L D H 2$ locus: random genetic drift, selection, and low level of recombination. Ann. Hum. Genet. 68, 93-109 (2004).

45. Osier, M. V. et al. A global perspective on genetic variation at the $\mathrm{ADH}$ genes reveals unusual patterns of linkage disequilibrium and diversity. Am. J. Hum. Genet. 71, 84-99 (2002)

46. Goldman, D. \& Enoch, M. A. Genetic epidemiology of ethanol metabolic enzymes: a role for selection. World Rev. Nutr. Diet. 63, 143-160 (1990).

47. Grant, B. F. et al. Co-occurrence of 12-month alcohol and drug use disorders and personality disorders in the United States: results from the National Epidemiologic Survey on Alcohol and Related Conditions. Arch. Gen. Psychiatry $6 \mathbf{1}$ 361-368 (2004)

48. Merikangas, K. R. et al. Comorbidity of substance use disorders with mood and anxiety disorders: results of the International Consortium in Psychiatric Epidemiology. Addict. Behav. 23, 893-907 (1998). 
49. Swendsen, J. D. \& Merikangas, K. R. The comorbidity of depression and substance use disorders. Clin. Psychol. Rev. 20, 173-189 (2000).

50. Clark, D. B., Cornelius, J. R., Kirisci, L. \& Tarter, R. E. Childhood risk categories for adolescent substance involvement: a general liability typology. Drug Alcohol Depend. 77, 13-21 (2005).

51. Wong, M. M., Zucker, R. A., Puttler, L. I. \& Fitzgerald, H. E. Heterogeneity of risk aggregation for alcohol problems between early and middle childhood: nesting structure variations. Dev. Psychopathol 11, 727-744 (1999).

52. Slutske, W. S. et al. Common genetic risk factors for conduct disorder and alcohol dependence. J. Abnorm. Psychol. 107, 363-374 (1998).

53. Grove, W. M. et al. Heritability of substance abuse and antisocial behavior: a study of monozygotic twins reared apart. Biol. Psychiatry 27, 1293-1304 (1990).

54. Cloninger, C. R., Bohman, M. \& Sigvardsson, S. Inheritance of alcohol abuse. Cross-fostering analysis of adopted men. Arch. Gen. Psychiatry 38, 861-868 (1981). A study of adoptees showing cross-inheritance of alcoholism and ASPD.

55. Virkkunen, M. \& Linnoila, M. Brain serotonin, type ॥ alcoholism and impulsive violence. J. Stud. Alcohol Suppl. 11, 163-169 (1993).

56. Grant, B. F. \& Dawson, D. A. Age of onset of drug use and its association with DSM-IV drug abuse and dependence: results from the National Longitudinal Alcohol Epidemiologic Survey. J. Subst. Abuse 10, 163-173 (1998). An epidemiological study showing that a delay in the onset of use is crucial to minimizing the lifetime burden of alcoholism

57. Faraone, S. V., Doyle, A. E., Mick, E. \& Biederman, J. Meta-analysis of the association between the 7-repeat allele of the dopamine $\mathrm{D}(4)$ receptor gene and attention deficit hyperactivity disorder. Am. J. Psychiatry 158, 1052-1057 (2001)

58. Brunner, H. G., Nelen, M., Breakefield, X. O., Ropers, H. H. \& van Oost, B. A. Abnormal behavior associated with a point mutation in the structural gene for monoamine oxidase A. Science 262, 578-580 (1993).

59. Caspi, A. et al. Role of genotype in the cycle of violence in maltreated children. Science 297, 851-854 (2002).

60. Crabbe, J. C. et al. Elevated alcohol consumption in null mutant mice lacking $5-\mathrm{HT}_{1 \mathrm{~B}}$ serotonin receptors. Nature Genet. 14, 98-101 (1996).

61. Soyka, M., Preuss, U. W., Koller, G., Zill, P. \& Bondy, B. Association of 5-HT1B receptor gene and antisocial behavior in alcoholism. J. Neural. Transm. 111, 101-109 (2004).

62. Kranzler, H. R., Hernandez-Avila, C. A. \& Gelernter, J. Polymorphism of the $5-\mathrm{HT} 1 \mathrm{~B}$ receptor gene (HTR1B): strong within-locus linkage disequilibrium without association to antisocial substance dependence. Neuropsychopharmacology 26, 115-222 (2002)

63. Porjesz, B. et al. Linkage and linkage disequilibrium mapping of ERP and EEG phenotypes. Biol. Psychol. $\mathbf{6 1}$ 229-248 (2002).

64. Becker, K., Laucht, M., El-Faddagh, M. \& Schmidt, M. H. The dopamine D4 receptor gene exon III polymorphism is associated with novelty seeking in 15-year-old males from a high-risk community sample. J. Neural Transm. 112, 847-858. (2005)

65. Sander, T. et al. Dopamine D4 receptor exon III alleles and variation of novelty seeking in alcoholics. Am. J. Med. Genet. 74, 483-487 (1997).

66. Kendler, K. S. et al. The structure of the genetic and environmental risk factors for six major psychiatric disorders in women. Phobia, generalized anxiety disorder, panic disorder, bulimia, major depression, and alcoholism. Arch. Gen. Psychiatry 52, 374-383 (1995).

67. Goldman, D. \& Barr, C. S. Restoring the addicted brain N. Engl. J. Med. 347, 843-845 (2002).

68. McEwen, B. S. Stress, adaptation, and disease. Allostasis and allostatic load. Ann. NY Acad. Sci. 840, 33-44 (1998).

69. Koob, G. F. \& Le Moal, M. Drug addiction, dysregulation of reward, and allostasis. Neuropsychopharmacology 24, 97-129 (2001).

\section{Highlights the relevance of using animal models to} understand the neuroadaptational processes that are crucial to addiction

70. Koss, M. P. et al. Adverse childhood exposures and alcohol dependence among seven Native American tribes. Am. J. Prev. Med. 25, 238-244 (2003).

71. Barr, C. S. et al. Serotonin transporter gene variation is associated with alcohol sensitivity in rhesus macaques exposed to early-life stress. Alcohol Clin. Exp. Res. 27, 812-817 (2003).

72. Chen, J. et al. Functional analysis of genetic variation in catechol-O-methyltransferase (COMT): effects on mRNA protein, and enzyme activity in postmortem human brain. Am. J. Hum. Genet. 75, 807-821 (2004).
73. Zhu, G. et al. Differential expression of human COMT alleles in brain and lymphoblasts detected by RT-coupled 5' nuclease assay. Psychopharmacology (Berl.) 177, 178-184 (2004).

74. $\mathrm{Xu}, \mathrm{K}$. et al. A catechol-O-methyltransferase haplotype is associated with heroin dependence. J. Med. Genet. (submitted).

75. Shifman, S. et al. A highly significant association between a COMT haplotype and schizophrenia. Am. J. Hum. Genet. 71, 1296-1302 (2002)

76. Diatchenko, L. et al. Genetic basis for individual variations in pain perception and the development of a chronic pain condition. Hum. Mol. Genet. 14, 135-143 (2005).

77. Egan, M. F. et al. Effect of COMT Val108/158Met genotype on frontal lobe function and risk for schizophrenia. Proc. Natl Acad. Sci. USA 98, 6917-6922 (2001).

A neurocognitive and neuroimaging paper showing that a functional COMT polymorphism alters frontal lobe function and cognition.

78. Malhotra, A. K. et al. A functional polymorphism in the COMT gene and performance on a test of prefrontal cognition. Am. J. Psychiatry 159, 652-654 (2002).

79. Goldberg, T. E. et al. Executive subprocesses in working memory: relationship to catechol-O-methyltransferase Val158Met genotype and schizophrenia. Arch. Gen. Psychiatry 60, 889-896 (2003).

80. Vandenbergh, D. J., Rodriguez, L. A., Miller, I. T., Uhl, G. R. \& Lachman, H. M. High-activity catechol-O-methyltransferase allele is more prevalent in polysubstance abusers. $\mathrm{Am}$. J. Med. Genet. 74, 439-442 (1997).

81. Tiihonen, J. et al. Association between the functional variant of the catechol-O-methyltransferase (COMT) gene and type 1 alcoholism. Mol. Psychiatry 4, 286-289 (1999).

82. Kauhanen, J. et al. Association between the functional polymorphism of catechol-O-methyltransferase gene and alcohol consumption among social drinkers. Alcohol Clin. Exp. Res. 24, 135-139 (2000)

83. Enoch, M. A., Xu, K., Ferro, E., Harris, C. R. \& Goldman, D. Genetic origins of anxiety in women: a role for a functional catechol-O-methyltransferase polymorphism. Psychiatr. Genet. 13, 33-41 (2003)

84. Zubieta, J. K. et al. COMT Val158Met genotype affects $\mu$-opioid neurotransmitter responses to a pain stressor. Science 299, 1240-1243 (2003). An imaging study showing that a functional polymorphism in COMT alters pain/stress resiliency.

85. Lesch, K. P. et al. Association of anxiety-related traits with a polymorphism in the serotonin transporter gene regulatory region. Science 274, 1527-1531 (1996).

86. Feinn, R., Nellissery, M. \& Kranzler, H. R. Meta-analysis of the association of a functional serotonin transporter promoter polymorphism with alcohol dependence. Am. J. Med. Genet. B 133, 79-84 (2005).

87. Sen, S., Burmeister, M. \& Ghosh, D. Meta-analysis of the association between a serotonin transporter promoter polymorphism (5-HTTLPR) and anxiety-related personality traits. Am. J. Med. Genet. B 127, 85-89 (2004).

88. Caspi, A. et al. Influence of life stress on depression: moderation by a polymorphism in the 5-HTT gene. Science 301, 386-389 (2003).

A pioneering study of gene-environment interactions.

89. Heinz, A. et al. A relationship between serotonin transporter genotype and in vivo protein expression and alcohol neurotoxicity. Biol. Psychiatry 47, 643-649 (2000).

90. Little, K. Y. et al. Cocaine, ethanol, and genotype effects on human midbrain serotonin transporter binding sites and mRNA levels. Am. J. Psychiatry 155, 207-213 (1998).

91. Hariri, A. R. et al. Serotonin transporter genetic variation and the response of the human amygdala. Science $\mathbf{2 9 7}$, 400-403 (2002).

\section{An imaging paper showing that a functional} polymorphism in the serotonin transporter alters the response to fearful stimuli in the amygdala.

92. Pezawas, L. et al. Interaction of SERT \& BDNF: Susceptibility for depression is reflected in morphometric changes of critical limbic circuits in humans. Neuropsychopharmacology 29, S200 (2004).

93. Smolka, M, L. et al. Additive effects of catecholO-methyltransferase Val158Met (COMT) and serotonin transporter (5-HTT) genotype on processing of adversive stimuli in the amygdala and hippocampus Science (submitted).

94. Nakamura, M., Ueno, S., Sano, A. \& Tanabe, H. The human serotonin transporter gene linked polymorphism (5-HTTLPR) shows ten novel allelic variants. Mol. Psychiatry 5, 32-38 (2000).

95. Hu, X. et al. The serotonin transporter promoter polymorphism is functionally triallelic and the gain-offunction allele is linked to obsessive-compulsive disorder. Neuron (submitted)

96. Weisner, C., Matzger, H. \& Kaskutas, L. A. How important is treatment? One-year outcomes of treated and untreated alcohol-dependent individuals. Addiction 98, 901-911 (2003).
97. Simpson, D. D., Joe, G. W. \& Broome, K. M. A national 5 -year follow-up of treatment outcomes for cocaine dependence. Arch. Gen. Psychiatry 59, 538-544 (2002).

98. O'Brien, C. P. A range of research-based pharmacotherapies for addiction. Science 278, 66-70 (1997).

An overview of the development of medication to treat addictions.

99. Johnson, B. A. An overview of the development of medications including novel anticonvulsants for the treatment of alcohol dependence. Expert. Opin. Pharmacother. 5, 1943-1955 (2004).

100. Pettinati, H. M. et al. Sertraline treatment for alcohol dependence: interactive effects of medication and alcoholic subtype. Alcohol Clin. Exp. Res. 24, 1041-1049 (2000).

101. Dundon, W., Lynch, K. G., Pettinati, H. M. \& Lipkin, C. Treatment outcomes in type A and $\mathrm{B}$ alcohol dependence 6 months after serotonergic pharmacotherapy. Alcohol Clin. Exp. Res. 28, 1065-1073 (2004)

102. Kulich, M., Rosenfeld, M., Goss, C. H. \& Wilmott, R. Improved survival among young patients with cystic fibrosis. J. Pediatr. 142, 631-636 (2003).

103. Nishimura, R. et al. Incidence of ESRD and survival after renal replacement therapy in patients with type 1 diabetes: a report from the Allegheny County Registry. Am. J. Kidney Dis. 42, 117-124 (2003)

104. Kupfer, D. J., First, M. B. \& Regier, D. A. (eds) A research agenda for DSM-V (American Psychiatric Association,

2002).

A comprehensive synthesis and analysis of the priorities in research to improve the classification of psychiatric diseases.

105. Babor, T. F. et al. Types of alcoholics. I. Evidence for an empirically derived typology based on indicators of vulnerability and severity. Arch. Gen. Psychiatry 49 599-608 (1992)

106. Zucker, R. A. The four alcoholisms: a developmental account of the etiologic process. Nebr. Symp. Motiv. 34 27-83 (1986)

107. Windle, M. \& Scheidt, D. M. Alcoholic subtypes: are two sufficient? Addiction 99, 1508-1519 (2004).

108. Morey, L. C. \& Skinner, H. A. Empirically derived classifications of alcohol-related problems. Recent. Dev. Alcohol 4, 145-168 (1986).

109. Hauser, J. \& Rybakowski, J. Three clusters of male alcoholics. Drug Alcohol Depend. 48, 243-250 (1997).

110. Feingold, A., Ball, S. A., Kranzler, H. R. \& Rounsaville, B. J. Generalizability of the type A/type B distinction across different psychoactive substances. Am. J. Drug Alcohol Abuse 22, 449-462 (1996).

111. Ball, S. A., Carroll, K. M., Babor, T. F. \& Rounsaville, B. J. Subtypes of cocaine abusers: support for a type A-type B distinction. J. Consult. Clin. Psychol. 63, 115-124 (1995).

112. Kalivas, P. W. \& McFarland, K. Brain circuitry and the reinstatement of cocaine-seeking behavior. Psychopharmacology (Berl.) 168, 44-56 (2003).

113. Nestler, E. J. Molecular mechanisms of drug addiction. Neuropharmacology 47 (Suppl. 1), 24-32 (2004).

114. Kalivas, P. W. Glutamate systems in cocaine addiction. Curr. Opin. Pharmacol. 4, 23-29 (2004).

115. Liu, Q. R. et al. Human brain derived neurotrophic factor (BDNF) genes, splicing patterns, and assessments of associations with substance abuse and Parkinson's disease. Am. J. Med. Genet. B 134, 93-103 (2005).

116. Lappalainen, J. et al. A functional neuropeptide Y Leu7Pro polymorphism associated with alcohol dependence in a large population sample from the United States. Arch. Gen. Psychiatry 59, 825-831 (2002)

117. Connor, J. P., Young, R. M., Lawford, B. R., Ritchie, T. L. \& Noble, E. P. $\mathrm{D}_{2}$ dopamine receptor (DRD2) polymorphism is associated with severity of alcohol dependence. Eur. Psychiatry 17, 17-23 (2002)

118. Berrettini, W. H., Ferraro, T. N., Alexander, R. C. Buchberg, A. M. \& Vogel, W. H. Quantitative trait loci mapping of three loci controlling morphine preference using inbred mouse strains. Nature Genet. 7, 54-58 (1994). QTL mapping of mouse opioid preference to the location of the $\mu$-opioid receptor, among other genomic regions.

119. Ferraro, T. N. et al. Confirmation of a major QTL influencing oral morphine intake in C57 and DBA mice using reciprocal congenic strains. Neuropsychopharmacology 30, 742-746 (2005).

120. Fehr, C., Shirley, R. L., Belknap, J. K., Crabbe, J. C. \& Buck, K. J. Congenic mapping of alcohol and pentobarbital withdrawal liability loci to $a<1$ centimorgan interval of murine chromosome 4: identification of $\mathrm{Mpdz}$ as a candidate gene. J. Neurosci. 22, 3730-3738 (2002).

121. Carr, L. G. et al. A quantitative trait locus for alcohol consumption in selectively bred rat lines. Alcohol Clin. Exp. Res. 22, 884-887 (1998). 
122. Demarest, K., Koyner, J., McCaughran, J. Jr, Cipp, L. \& Hitzemann, R. Further characterization and high-resolution mapping of quantitative trait loci for ethanol-induced locomotor activity. Behav. Genet. 31, 79-91 (2001).

123. Moore, M. S. et al. Ethanol intoxication in Drosophila: genetic and pharmacological evidence for regulation by the cAMP signaling pathway. Cell 93, 997-1007 (1998).

124. Matthes, H. W. et al. Loss of morphine-induced analgesia, reward effect and withdrawal symptoms in mice lacking the $\mu$-opioid-receptor gene. Nature $\mathbf{3 8 3}$, 819-823 (1996).

125. Picciotto, M. R. et al. Acetylcholine receptors containing the $\beta 2$ subunit are involved in the reinforcing properties of nicotine. Nature 391, 173-177 (1998).

Shows that the mouse knockout for the $\beta 2$ nicotinic receptor gene loses both nicotine preference and nicotine binding in the brain.

126. Olive, M. F. \& Messing, R. O. Protein kinase C isozymes and addiction. Mol. Neurobiol. 29, 139-154 (2004).

127. Thiele, T. E., Marsh, D. J., Ste Marie, L., Bernstein, I. L. \& Palmiter, R. D. Ethanol consumption and resistance are inversely related to neuropeptide Y levels. Nature 396, 366-369 (1998).

128. van den Bree, M. B., Johnson, E. O., Neale, M. C. \& Pickens, R. W. Genetic and environmental influences on drug use and abuse/dependence in male and female twins. Drug Alcohol Depend. 52, 231-241 (1998).

129. Lynskey, M. T. et al. Genetic and environmental contributions to cannabis dependence in a national young adult twin sample. Psychol. Med. 32, 195-207 (2002).

130. Kendler, K. S. \& Prescott, C. A. Cannabis use, abuse, and dependence in a population-based sample of female twins. Am. J. Psychiatry 155, 1016-1022 (1998).

131. Tsuang, M. T. et al. Genetic influences on DSM-III-R drug abuse and dependence: a study of 3,372 twin pairs. Am. J. Med. Genet. 67, 473-477 (1996).

132. Kendler, K. S., Karkowski, L. \& Prescott, C. A. Hallucinogen, opiate, sedative and stimulant use and abuse in a population-based sample of female twins. Acta. Psychiatr. Scand. 99, 368-376 (1999).
133. Kendler, K. S. \& Prescott, C. A. Cocaine use, abuse and dependence in a population-based sample of female twins. Br. J. Psychiatry 173, 345-350 (1998)

134. True, W. R. et al. Common genetic vulnerability for nicotine and alcohol dependence in men. Arch. Gen. Psychiatry 56, 655-661 (1999).

135. Kendler, K. S., Thornton, L. M. \& Pedersen, N. L. Tobacco consumption in Swedish twins reared apart and reared together. Arch. Gen. Psychiatry 57, 886-892 (2000).

136. Kendler, K. S. et al. A population-based twin study in women of smoking initiation and nicotine dependence. Psychol. Med. 29, 299-308 (1999).

137. Heath, A. C. \& Martin, N. G. Genetic models for the natural history of smoking: evidence for a genetic influence on smoking persistence. Addict. Behav. 18, 19-34 (1993)

138. Heath, A. C. et al. Genetic and environmental contributions to alcohol dependence risk in a national twin sample: consistency of findings in women and men. Psychol. Med. 27, 1381-1396 (1997)

139. Prescott, C. A. \& Kendler, K. S. Genetic and environmental contributions to alcohol abuse and dependence in a population-based sample of male twins. Am. J. Psychiatry 156, 34-40 (1999).

140. Kendler, K. S., Heath, A. C., Neale, M. C., Kessler, R. C. \& Eaves, L. J. A population-based twin study of alcoholism in women. JAMA 268, 1877-1882 (1992).

141. Carmelli, D., Heath, A. C. \& Robinette, D. Genetic analysis of drinking behavior in World War II veteran twins. Genet. Epidemiol. 10, 201-213 (1993).

142. Hettema, J. M., Corey, L. A. \& Kendler, K. S. A multivariate genetic analysis of the use of tobacco, alcohol, and caffeine in a population based sample of male and female twins. Drug Alcohol Depend. 57, 69-78 (1999).

143. Kendler, K. S. \& Prescott, C. A. Caffeine intake, tolerance, and withdrawal in women: a population-based twin study. Am. J. Psychiatry 156, 223-228 (1999).

144. Eisen, S. A. et al. Familial influences on gambling behavior: an analysis of 3359 twin pairs. Addiction 93, 1375-1384 (1998).
Acknowledgements

We gratefully acknowledge E. Gordis for his helpful comments on this manuscript.

Competing interests statement

The authors declare no competing financial interests.

\section{(2) Online links}

\section{DATABASES}

The following terms in this article are linked online to:

Entrez Gene: http://www.ncbi.nlm.nih.gov/entrez/query.

fcgi?db=gene

ADH1B |ALDH2 | BRCA1 | COMT | DRD4 | HTR1B | MAOA

OMIM: http://www.ncbi.nlm.nih.gov/entrez/query.

fcgi?db=OMIM

schizophrenia | type 1 diabetes

\section{FURTHER INFORMATION}

Collaborative Study on the Genetics of Alcoholism: www. niaaa.nih.gov/extramural/projcoga.htm

International HapMap Project: http://www.hapmap.org National Institute on Drug Abuse Genetic Consortium: http://www.nida.nih.gov/about/organization/Genetics/ consortium

National Institute on Drug Abuse report - Addiction burden in the USA: http://www.drugabuse.gov/about/ welcome/aboutdrugabuse/magnitude

Request proposals for access to a whole genome

association scanning resource to identify addiction loci: www.drugabuse.gov/about/organization/genetics/SNP.html World Health Organization - Global status report on alcohol, 2004: http://www.who.int/substance_abuse/ publications/en/global_status_report_2004_overview.pdf World Health Organization report - The global burden of addiction: http://www.who.int/substance_abuse/facts/global burden/en

Access to this interactive links box is free online. 